\title{
RANCANG BANGUN MEKANISME PENINGKAT PUTARAN BERTENAGA SEPEDA STATIS DENGAN KELUARAN 2700 RPM PADA SISTEM ALTERNATOR
}

\author{
Gede Andhika Sindhu Artha ${ }^{(1)}$, Djoko Herwanto ${ }^{(2)}$, Amal Fatkhulloh ${ }^{(3)}$ \\ 1,2,3 Politeknik Penerbangan Indonesia Curug \\ e-mail: ' gedeandhikasinduartha.ppicurug@gmail.com, \\ 2djoko.herwanto@ppicurug.ac.id, ${ }^{3}$ amal.fatkhulloh@ppicurug.ac.id
}

\begin{abstract}
Abstrak: Dalam engine run, dapat disimulasikan memanfaatkan putaran roda sepeda statis untuk memenuhi kebutuhan putaran alternator. Namun, keterbatasan kayuhan otot kaki manusia belum mampu mencapai rpm yang diinginkan. Dengan demikian dibutuhkan mekanisme peningkat putaran. Berdasarkan beberapa identifikasi masalah yang akan menjadi batasan masalah adalah bagaimana merancang mekanisme peningkat putaran bertenaga sepeda statis dengan keluaran $2700 \mathrm{rpm}$. Dari hasil rancangan ini, didapatkan knurling wheel dengan permukaan diamond pattern knurling berdiameter $60 \mathrm{~mm}$ sebagai penerus putaran roda sepeda berdiameter $660 \mathrm{~mm}$. Roda gigi yang dipilih adalah roda gigi lurus dimana roda gigi penggerak berjarak bagi $120 \mathrm{~mm}$, jumlah gigi 60 dan roda gigi yang digerakkan berjarak bagi $60 \mathrm{~mm}$ dengan jumlah gigi 30 untuk menaikkan putaran dari knurling wheel. Poros yang digunakan berdiameter $20 \mathrm{~mm}$ dengan ukuran pasak $7 \times 7$. Bearing yang digunakan adalah tipe ball bearing dengan nomor bantalan 6004. Pada sabuk dan puli, perancang memilih sabuk v tipe A nomor 35 dengan panjang keliling sabuk $889 \mathrm{~mm}$ dan puli penggerak berdiameter $127 \mathrm{~mm}$. Penyangga (roda gigi, puli dan alternator) yang digunakan bermaterial S45C dengan yield strength $343 \mathrm{~N} / \mathrm{mm}^{2}$. Dari hasil perhitungan dan perancangan yang telah dilakukan, alat yang dibuat bekerja dengan baik sesuai kriteria perancang. Sehingga rancangan ini dapat digunakan untuk membantu menaikkan putaran dari input putaran roda sepeda.
\end{abstract}

Kata Kunci: Alternator, peningkat putaran, Sepeda statis.

Abstract: $\quad$ Manufacturing of gas turbine engine was started by identification of some components and systems involve in building the gas turbine engine. A turbocharger which consist of turbine and compressor as the main part was taken to make a turbine and compressor in Gas turbine engine. Those component is also the essential part of the machine. To operate the gas turbine engine, it is important to design some system such as Oil system,

http://journal.ppicurug.ac.id/index.php/jurnal-langit-biru 
fuel System, Ignition System, combustion chamber, and others. In this design project the writer obtains the task to design the oil system that fit and suitable for this type of gas turbine engine. Any issue related to this design such as how to decide the viscosity of the oil, calculate critical pressure of bearing, calculate mass of the oil fluid, head pressure of the pump and reservoir capacity. The final outcome of this design is correct supply of the oil flow which is used to lubricate shaft bearing in gas turbine engine. This system also prevent the machine from over heating that can degrade components of the engine due to metal to metal contact. From the final calculation found 37 psi oil pressure is needed to lubricate shaft bearing and can maintain the continuous operation of the engine.

Keyword: Alternator, rotation enhancer, Static bike.

\section{PENDAHULUAN}

\section{Latar Belakang}

Sistem alternator berfungsi mengisi battery dan mensuplai arus listrik ke sistem kelistrikan pesawat. Sebagai sumber tenaga listrik, alternator harus menanggung berbagai jenis keadaan mulai dari iddle, taxy, take-off, climbing, cruising, descend, landing approach, dan landing roll. Tiap tahapan penerbangan tersebut memiliki langkah kerja terkait dengan beban listrik. Sehingga penambahan beban listrik berakibat semakin kecil nilai total hambatan sekaligus bertambah nilai arus totalnya dan keluaran tenaga alternator. Pada Program Studi Teknik Pesawat Udara Sekolah Tinggi Penerbangan Indonesia taruna melakukan praktek engine run. Pada praktek tersebut dilakukan pemutaran engine dari $1000 \mathrm{rpm}$ sampai $2000 \mathrm{rpm}$. Sebagai contoh dalam memastikan nilai voltage pada saat $2000 \mathrm{rpm}$ sebesar $28+/-$ 1 volt. Dengan pembebanan maksimal saat take off sebesar 24 ampere mengakibatkan berkurangnya putaran engine dalam sesaat dikarenakan kebutuhan torsi meningkat.

Dalam engine run, dapat disimulasikan memanfaatkan putaran roda sepeda statis untuk memenuhi kebutuhan putaran alternator. Namun, keterbatasan kayuhan otot kaki manusia belum mampu mencapai rpm yang diinginkan. Hal tersebut tercantum dalam hasil penelitian analisa tingkat kekuatan otot kaki manusia bersepeda oleh Erick Rinaldi, dimana variasi tinggi badan dan berat badan memengaruhi kekuatan otot kaki manusia. Oleh karena itu dibutuhkan mekanisme penaik putaran.

Dari permasalahan tersebut, perancang tertarik untuk membuat rancang bangun sistem penggerak alternator dengan mekanisme kerjanya menggunakan penaik putaran. Oleh karena itu, perancang membuat karya dengan judul: RANCANG BANGUN MEKANISME PENINGKAT PUTARAN BERTENAGA SEPEDA STATIS DENGAN KELUARAN 2700 RPM PADA SISTEM ALTERNATOR 
Rancang Bangun Mekanisme Peningkat Putaran Bertenaga Sepeda Statis Dengan Keluaran 2700 Rpm Pada Sistem Alternator

METODOLOGI PERANCANGAN

Desain Perancangan

Kondisi saat ini

Hangar 01 Program Studi Teknik

Pesawat Udara Sekolah Tinggi

Penerbangan Indonesia terdapat ruangan electrical shop. Di ruangan tersebut terdapat sepeda yang belum dimanfaatkan dengan baik. Perancang ingin membuat suatu inovasi dengan memanfaatkan sepeda untuk memutar alternator sehingga dapat menghasilkan energi listrik. Namun, kekuatan otot kaki manusia mengayuh sepeda terbatas dan tidak dapat mencapai minimum rpm alternator. Oleh karena itu dibutuhkan mekanisme penaik putaran.

\section{Kondisi yang diinginkan}

Untuk menyelesaikan permasalah di atas dan untuk mengimplementasikan teori yang telah dikemukakan, maka perancang bertujuan membuat mekanime peningkat putaran bertenaga sepeda statis. Dengan terciptanya rancang bangun mekanisme ini diharapkan mampu mencapai minimum putaran alternator dan mampu merasakan beban torsi dan putaran selama memutar alternator.

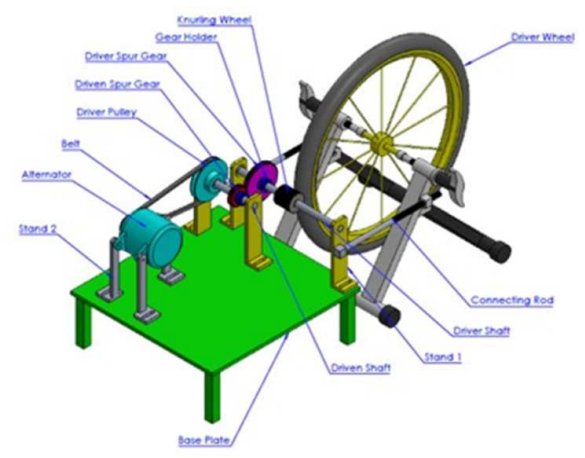

Gambar 1. Mekanisme Peningkat Putaran Bertenaga Sepeda Statis

\section{Tahapan Perancangan}

Pada tahapan perancangan ini, akan dibahas mengenai perhitungan yang mendasari rancangan bangun mekanisme peningkat putaran roda gigi dengan keluaran 2700 rpm. Perhitunganperhitungan terhadap perancangan disesuaikan dengan rumusan masalah :

1. Memilih dudukan sepeda jenis friction bicycle trainer

Berdasarkan data spesifikasi sepeda yang digunakan dan data spesifikasi dudukan sepeda (friction bicycle trainer), maka kriteria pemilihan dudukan sepeda jenis friction bicycle trainer adalah:

a. Mampu menahan beban sepeda sebesar $15 \mathrm{~kg}$

b. Mampu menahan beban orang yang mengayuh sepeda, disini perancang membatasi $70 \mathrm{~kg}$

c. Ukuran dimensi bicycle trainer sesuai untuk ukuran roda sepeda 26 " dan rear wheel axle sepeda 7"

2. Merancang adjustment penghubung antara dudukan sepeda dan penyangga roda gigi

Untuk merencanakan baut (batang hubung antara dudukan sepeda dan penyangga roda gigi), maka beban yang diterima adalah massa dari sepeda sebesar $15 \mathrm{~kg}$ merupakan beban yang ditanggung oleh dudukan sepeda.

a. Beban rencana

Jika faktor keamanan 8 maka beban rencana w sebagai patokan adalah

$$
\mathrm{W}=f_{S} \times w
$$

Dengan

$\mathrm{W}$ : Beban rencana $(\mathrm{kg})$

$$
\begin{aligned}
& f_{s}: \text { Faktor keamanan } \\
& \mathrm{w}: \text { beban asli }(\mathrm{kg})
\end{aligned}
$$




$$
\begin{aligned}
\mathrm{W} & =8 \times 15 \mathrm{~kg} \\
\mathrm{~W} & =120 \mathrm{~kg}
\end{aligned}
$$

Menentukan diameter

$$
d \geq \sqrt{\frac{4 w}{\pi \sigma a \times 0,64}}
$$

Dengan

$\mathrm{d}=$ Diameter luar $(\mathrm{mm})$

$\mathrm{W}=$ Beban rencana $(\mathrm{kg})$

$\sigma_{\mathrm{a}}=$ Tegangan yang dizinkan

$$
d \geq \sqrt{\frac{4 \times 120}{3,14 \times 4,8 \times 0,64}}
$$

$d \geq \sqrt{49,8}$

$d \geq 7,05 \mathrm{~mm}$

Karena diameter ulir menyesuaikan dengan diameter batang penghubung antara dudukan sepeda dan penyangga roda gigi penggerak sebesar $16 \mathrm{~mm}$, maka perancang memilih ulir metris kasar M16 dengan bahan baja yang tersedia di pasaran

$\mathrm{d}=16,000 \mathrm{~mm}, \mathrm{~d}_{2}=14,701 \mathrm{~mm}, \mathrm{~d}_{1}=$ $13,835 \mathrm{~mm}, \mathrm{p}=2 \mathrm{~mm}$.

Panjang baut sebesar $400 \mathrm{~mm}$ dan sepanjang baut dibuat berulir dengan jumlah ulirnya 180 .

3. Menentukan knurling wheel jenis diamond pattern knurling

Menentukan diameter knurling wheel dengan permukaan diamond pattern knurling karena bagian permukaannya memiliki grip yang lebih baik untuk meneruskan putaran dari roda sepeda dimana putaran roda sepeda berdasarkan lampiran 24. Kecepatan mengayuh roda sepeda adalah 16,7 km/jam dikonversi menurut diameter roda sepeda sebesar $660 \mathrm{~mm} \quad\left(\mathrm{~d}_{1}\right)$. Spesikasi
Sepeda United Miami XC 02 menjadi 134,3 rpm $\left(\mathrm{N}_{1}\right)$, kecepatan yang akan dicapai sebesar 1477,3 $\mathrm{rpm}\left(\mathrm{N}_{2}\right)$.

$$
\begin{gathered}
\frac{N_{2}}{N_{1}}=\frac{d_{1}}{d_{2}} \\
\frac{1477,3}{134,3}=\frac{660}{d_{2}}
\end{gathered}
$$

$d_{2}=60 \mathrm{~mm}$

Jadi, diameter knurling wheel $\left(d_{2}\right)$ adalah $60 \mathrm{~mm}$.

4. Merancang roda gigi penggerak (gigi lurus) dan roda gigi yang digerakkan (gigi lurus)

Roda gigi ini digunakan untuk meneruskan putaran dari roda sepeda melalui knurling wheel. Roda gigi lurus ini terdiri dari 2 buah roda gigi lurus, dimana roda gigi 1 sebagai roda gigi penggerak dimana satu poros dengan knurling wheel dan roda gigi 2 sebagai roda gigi yang digerakkan mendapat putaran dari roda gigi 1 .

Menghitung daya rencana.

$\mathrm{P}_{\mathrm{d}}=\mathrm{f}_{\mathrm{c}} \times \mathrm{P}$

$=1,2 \times 0,98=1,176 \mathrm{~kW}$

Menghitung diameter lingkaran jarak bagi roda gigi besar

$d^{\prime}{ }_{1}=\frac{2 \cdot a}{(1+i)}$

$d^{\prime}{ }_{1}=\frac{2.90}{(1+0,5)}$

$d^{\prime}{ }_{l}=\frac{180}{(1,5)}=120 \mathrm{~mm}$

Menghitung diameter lingkaran jarak bagi roda gigi pinion

$d_{2}^{\prime}=\frac{2 \cdot a \cdot i}{(1+i)}$

$d_{2}^{\prime}=\frac{2.90 \cdot 0,5}{(1+0,5)}=60 \mathrm{~mm}$

Pemilihan modul, $\mathrm{m}=2, \alpha_{\mathrm{o}}=20^{\circ}$

Menentukan jumlah gigi $\mathrm{z}_{1}, \mathrm{Z}_{2}$ dan perbandingan roda gigi $i$

$\mathrm{z}_{1}=120 / 2=60$

$\mathrm{z}_{2}=60 / 2=30$ 
Rancang Bangun Mekanisme Peningkat Putaran Bertenaga Sepeda Statis Dengan Keluaran 2700 Rpm Pada Sistem Alternator

$i=30 / 60=0,5$ (roda gigi peningkat putaran 2x)

Menghitung diameter lingkaran jarak bagi $\mathrm{d}_{01}, \mathrm{~d}_{02}$ dan jarak sumbu poros $a_{\mathrm{o}}$ $\mathrm{d}_{01}=60 \times 2=120 \mathrm{~mm}$

$\mathrm{d}_{02}=30 \times 2=60 \mathrm{~mm}$

$a_{0}=(120+60) / 2=90 \mathrm{~mm}$

Diameter kepala $\mathrm{d}_{\mathrm{k} 1}, \mathrm{~d}_{\mathrm{k} 2}$ :

$\mathrm{d}_{\mathrm{k} 1}=(60+2) \times 2=124 \mathrm{~mm}$

$\mathrm{d}_{\mathrm{k} 2}=(30+2) \times 2=64 \mathrm{~mm}$

5. Merancang poros

Sebuah poros akan mendapatkan pembebanan utama berupa torsi, disamping beban lenturan yang diakibatkan oleh roda gigi, sehingga beban tersebut akan diperhitungkan sebagai pembebanan tambahan dalam faktor keamanan yang diambil.

Daya : 980 Watt $(0,98 \mathrm{~kW})$, Putaran 1477,3 RPM

Faktor Koreksi $\left(f_{c}\right)=1,2$ (faktor keamanan dalam perencanaan berdasarkan daya yang akan ditransmisikan.

Daya yang direncanakan berdasarkan $P_{d}=f_{c} . P=1,2 \times 0,98=1,176(\mathrm{~kW})$

Jika daya yang direncanakan adalah 1,176 kW maka momen puntir rencana $(\mathrm{T})$ adalah

$$
\begin{aligned}
\mathrm{T} & =9,74 \times 10^{5} \times \frac{P d}{n 1} \\
& =9,74 \times 10^{5} \times \frac{1,176}{1477,3}=775,35
\end{aligned}
$$

(kg.mm)

Bahan poros yang digunakan adalah Baja SNCM 1 (Chrom Nikel Molibdenum). Mempunyai kekuatan tarik, $\sigma_{\mathrm{B}} 85 \frac{\mathrm{kg}}{\mathrm{mm}^{2}}, S f_{1}=6,0, S f_{2}=1,3$.

Tegangan geser yang diizinkan.

$\tau_{a}=\sigma_{B} /\left(S f_{1} \times S f_{2}\right)$

$\tau_{a}=85 /(6,0 \times 1,3)$

$\tau_{a}=10,90 \frac{\mathrm{kg}}{\mathrm{mm}^{2}}$
Faktor koreksi momen puntir, $\mathrm{K}_{\mathrm{t}}=$ 1,5 (beban yang dikenakan secara tiba-tiba), faktor koreksi untuk beban lentur, $\mathrm{C}_{\mathrm{b}}=2,0$.

Setelah diketahui tegangan geser yang diizinkan, diameter poros dapat ditentukan

$$
\begin{aligned}
\mathrm{d}_{\mathrm{s}} & =\left[\frac{5,1}{\tau_{a}} K_{t} C_{b} T\right]^{1 / 3} \\
& =\left[\frac{5,1}{10,90} \times 1,5 \times 2,0 \times 775,35\right]^{1 / 3} \\
& =[1088,335]^{1 / 3} \\
& =10,28 \mathrm{~mm} \\
& =10,3 \mathrm{~mm}
\end{aligned}
$$

jari-jari filet $=(12,5-10,3) / 2=1,1 \mathrm{~mm}$ Alur pasak $5 \times 3 \times$ filet 0,16

Tegangan geser

$\tau=\frac{5,1 T}{d_{s}{ }^{3}}=\frac{5,1(775,35)}{(10,26)^{3}}=\frac{3954,285}{1080,045}=$ $3,61\left(\mathrm{~kg} / \mathrm{mm}^{2}\right)$

Dan membandingkan apakah $\frac{\sigma_{\alpha} \cdot S_{f 2}}{\alpha}>$

$K_{t} \cdot C_{b} \cdot \tau$

$\frac{\sigma_{\alpha} \cdot S_{f 2}}{\alpha}: K_{t} \cdot C_{b} \cdot \tau$

$\frac{10,9 \times 1,3}{2,6}: 1,5 \times 2,0 \times 3,61$

$5,45: 10,83$ (karena perbandingan tidak mendapatkan $\frac{\sigma_{\alpha} \cdot S_{f 2}}{\alpha}>K_{t} \cdot C_{b} \cdot \tau$ maka ulangi langkah sebelumnya)

Anggaplah diameter $d_{s}=20 \mathrm{~mm}$ Diameter bagian bantalan $22 \mathrm{~mm}$ Jari-jari filet (22-20)/2 $=1,0 \mathrm{~mm}$ Alur pasak 7 x 4,0 x 0,4

6. Memilih bearing

Jenis ball bearing dipilih karena beban utama yang didapatkan oleh alat penggerak adalah beban dorong (thrust load). Bahan poros adalah Steel Nickel Chrom Molybdenum (SNCM) 1 dengan tegangan lentur $\sigma_{\mathrm{a}}$ $=80 \mathrm{~kg} / \mathrm{mm}^{2}$ dan tegangan tarik $\sigma_{\mathrm{B}}=$ $85\left(\mathrm{~kg} / \mathrm{mm}^{2}\right)$. 
Berdasarkan perhitungan beban dinamis dan beban statis roda gigi lurus, telah diketahui beban dinamis sebesar 511,0389 $\mathrm{kg}$ dan beban dinamis sebesar 466,64 $\mathrm{kg}$ maka penulis memilih tipe ball ball bearing dengan nomor bantalan 6004 dengan kapasitas nominal dinamis sebesar $735 \mathrm{~kg}$ dan kapasitas nominal statis sebesar $456 \mathrm{~kg}$.

7. Memilih sabuk dan puli

Perhitungan daya yang akan ditransmisikan $P(\mathrm{~kW})$, putaran poros $N_{l}(\mathrm{rpm})$, perbandingan putaran $i$, dan jarak sumbu poros $C(\mathrm{~mm})$.

$P=980$ watt $=0,98 \mathrm{~kW}$

$N_{l}=2954,6 \mathrm{rpm}$

$N_{2}=6000 \mathrm{rpm}$ (putaran alternator maksimum)

$i=\frac{N_{1}}{N_{2}}$

$i=\frac{2954,6}{6000}$

$i=0,4924$

$C=290 \mathrm{~mm}$

Perhitungan daya rencana $P_{d}(\mathrm{~kW})$

$$
\begin{aligned}
P_{d} & =f_{c} \times P \\
& =1,2 \times 0,98 \\
& =1,176 \mathrm{~kW}
\end{aligned}
$$

Pemilihan penampang sabuk

Berdasarkan lampiran dan kondisi pasaran dengan ukuran untuk putaran $6000 \mathrm{rpm}$, maka penampang sabuk V yang dipilih bertipe A. Perhitungan diameter puli $d_{l}$ adalah diameter puli penggerak d2 adalah diameter puli yang digerakkan

Karena berpatokan pada puli alternator yang ada sebesar $65 \mathrm{~mm}$ maka perhitungan menjadi :

$\frac{N_{2}}{N_{1}}=\frac{d_{1}}{d_{2}}$ $\frac{6000}{2954,6}=\frac{d_{1}}{62,53}$

$\mathrm{d}_{1}=375180 / 2954,6$

$\mathrm{d}_{1}=126,98 \mathrm{~mm} \quad \mathrm{~d}_{1}=$

$127 \mathrm{~mm}$

Perhitungan kecepatan linier sabuk $v=\frac{\pi \cdot d_{1} \cdot N_{1}}{60 \times 1000}$ kecepatan linier sabuk

$<30 \mathrm{~m} / \mathrm{s}$

$=\frac{3,14 \times 127 \times 2954,6}{60000}$

$=19,63 \mathrm{~m} / \mathrm{s}$ $<30$

$\mathrm{m} / \mathrm{s}$

Perhitungan Panjang keliling sabuk $L$ (mm)

$\mathrm{L}=2 \mathrm{C}+\frac{\pi}{2}(\mathrm{~d} 2+\mathrm{d} 1)+\frac{1}{4 c}+(\mathrm{d} 2-$

d1) $)^{2}$

$\mathrm{L}=2(290)+\frac{3,14}{2}(127+62,53)+$

$\frac{1}{4(290)}(127-62,53)^{2}$

$\mathrm{L}=580+297,56+3,58$

$\mathrm{L}=881,14 \mathrm{~mm}$

Nomor nominal dan Panjang sabuk

$\mathrm{V}$ dalam perdagangan

Sabuk V Tipe A No. 35 dengan $\mathrm{L}=$ $889 \mathrm{~mm}$

8. Merancang penyangga (roda gigi, puli dan alternator)

a. Merancang penyangga (roda gigi penggerak dan knurling wheel)

Menentukan momen gaya yang bekerja pada perancangan.

Untuk mendapatkan gaya berat. Diketahui massa roda gigi penggerak adalah 1279,69 $\mathrm{gr}=$ $1,27969 \mathrm{~kg}$. Massa roda gigi penggerak, massa knurling wheel adalah $1145,57 \mathrm{gr}=1,14557 \mathrm{~kg}$ Massa knurling wheel dan massa total keduanya adalah $2,42526 \mathrm{~kg}$, gravitasi adalah $9,8 \mathrm{~m} / \mathrm{s}^{2}$.

$\mathrm{W}=\mathrm{m} \times \mathrm{g}$

$\mathrm{W}=2,42526 \times 9,8$ 
Rancang Bangun Mekanisme Peningkat Putaran Bertenaga Sepeda Statis Dengan Keluaran 2700 Rpm Pada Sistem Alternator

$\mathrm{W}=23,76 \mathrm{~N}$

Gaya tangensial roda gigi diperoleh sebesar 134,14 N.

Jadi, total beban yang diterima adalah $23,76+134,14=157,9 \mathrm{~N}$.

Menentukan tegangan ijin material

Faktor keamanan diperlukan dalam proses perancangan, maka perancang menentukan faktor keamanan sebesar 8 karena menggunakan material steel dan menerima beban hidup, sehingga didapatkan :

$\sigma_{\text {allow }}=\frac{\text { yield strength }}{\text { factor of safety }}$ $=\frac{343}{8}=42,875 \mathrm{~N} / \mathrm{mm}^{2}$

b. Merancang penyangga (roda gigi yang digerakkan dan puli)

Menentukan momen gaya yang bekerja pada perancangan.

Untuk mendapatkan gaya berat. Diketahui massa roda gigi yang digerakkan adalah 287,25 gr = $0,28725 \mathrm{~kg}$, massa puli adalah $1686,29 \mathrm{gr}=1,68629 \mathrm{~kg}$ lihat lampiran 23 dan massa total keduanya adalah1,97354 kg, gravitasi adalah $9,8 \mathrm{~m} / \mathrm{s}^{2}$.

$\mathrm{W}=\mathrm{m} \times \mathrm{g}$

$\mathrm{W}=1,97354 \times 9,8$

$\mathrm{W}=19,34 \mathrm{~N}$

Gaya tangensial roda gigi berdasarkan perhitungan

diperoleh sebesar 134,14 N.

Jadi, total beban yang diterima adalah $19,34+134,14=153,5 \mathrm{~N}$.

Menentukan tegangan ijin material

Faktor keamanan diperlukan dalam proses perancangan, maka perancang menentukan faktor keamanan sebesar 8 karena menggunakan material steel dan menerima beban hidup, sehingga didapatkan :

$\sigma_{\text {allow }}=\frac{\text { yield strength }}{\text { factor of safety }}$

$=\frac{343}{8}=42,875 \mathrm{~N} / \mathrm{mm}^{2}$

c. Merancang penyangga alternator

Menentukan momen gaya yang bekerja pada perancangan.

Untuk mendapatkan gaya berat. Diketahui massa alternator adalah $13 \mathrm{lbs}=5,89 \mathrm{~kg}$, gravitasi adalah $9,8 \mathrm{~m} / \mathrm{s}^{2}$.

$\mathrm{W}=\mathrm{m} \times \mathrm{g}$

$\mathrm{W}=5,89 \times 9,8$

$\mathrm{W}=57,72 \mathrm{~N}$

Menentukan tegangan ijin material

Faktor keamanan diperlukan dalam proses perancangan, maka perancang menentukan faktor keamanan sebesar 8 karena menggunakan material steel dan menerima beban hidup, sehingga didapatkan :

$\sigma_{\text {allow }}=\frac{\text { yield strength }}{\text { factor of safety }}$

$=\frac{343}{8}=42,875 \mathrm{~N} / \mathrm{mm}^{2}$

\section{Uji Coba Rancangan}

Setelah dilakukan proses perancangan, selanjutnya dilakukan uji coba rancangan dengan objek uji sesuai dengan kriteria yang diinginkan. penulis melakukan uji coba terhadap alat yang telah dibuat. Uji coba rancangan terdiri dari uji coba blok rancangan dan uji coba fungsi. Berikut disampaikan hasil pengujian rancang bangun mekanisme peningkat putaran bertenaga sepeda statis dengan keluaran $2700 \mathrm{rpm}$. 
Langit Biru: Jurnal Ilmiah Aviasi Vol. 14 No. 1 Februari 2021

ISSN (p) 1979-1534 ISSN (e) 2745-8695

1. Uji Coba Blok Rancangan

Tabel 1. Uji Coba blok rancangan

\begin{tabular}{|c|c|c|c|c|c|}
\hline No. & \multicolumn{2}{|c|}{ Blok Rancangan } & Hasil & Indikator & Keterangan \\
\hline 1 & \multicolumn{2}{|c|}{$\begin{array}{l}\text { Dudukan Sepeda jenis friction } \\
\text { bicycle trainer }\end{array}$} & $\begin{array}{l}\text { - Mampu menahan } \\
\text { beban sepeda } \\
\text { sebesar } 15 \mathrm{~kg} \\
\text { - Mampu menahan } \\
\text { beban pengayuh } \\
70 \mathrm{Kg} \\
\text { - Kompatibel } \\
\text { dengan ukuran } \\
\text { roda sepeda 26" } \\
\text { dan rear wheel } \\
\text { axle 7" }\end{array}$ & $\begin{array}{l}\text { - Mampu menahan } \\
\text { beban sepeda } \\
\text { sebesar } 15 \mathrm{~kg} \\
\text { - Mampu menahan } \\
\text { beban pengayuh } \\
70 \mathrm{Kg} \\
\text { - Kompatibel } \\
\text { dengan ukuran } \\
\text { roda sepeda 26" } \\
\text { dan rear wheel } \\
\text { axle 7" }\end{array}$ & Sesuai \\
\hline 2 & $\begin{array}{l}\text { Adjustment } \\
\text { penghubung } \\
\text { antara dudukan } \\
\text { sepeda dan } \\
\text { penyangga roda } \\
\text { gigi }\end{array}$ & $\begin{array}{l}\text { Ulir } \\
\text { Pengikat }\end{array}$ & $\begin{array}{l}\text { Ulir metris kasar } \\
\text { M16 dengan } \\
\text { diameter luar (D) } 16 \\
\text { mm dan diameter } \\
\text { dalam (D }\left(_{1}\right) 13,835 \\
\text { mm }\end{array}$ & $\begin{array}{l}\text { Ulir metris kasar } \\
\text { M16 dengan } \\
\text { diameter luar (D) } 16 \\
\text { mm dan diameter } \\
\text { dalam (D } 1 \text { ) } 13,835 \\
\text { mm }\end{array}$ & Sesuai \\
\hline 3 & \multicolumn{2}{|c|}{$\begin{array}{l}\text { Knurling wheel jenis diamond } \\
\text { pattern knurling }\end{array}$} & Diameter $60,20 \mathrm{~mm}$ & Diameter $60 \mathrm{~mm}$ & Sesuai \\
\hline \multirow[t]{2}{*}{4} & \multirow[t]{2}{*}{ Roda gigi lurus } & $\begin{array}{l}\text { Roda gigi } \\
\text { penggerak }\end{array}$ & $\begin{array}{l}\text { Diameter kepala } \\
\left(\mathrm{d}_{\mathrm{k} 1}\right) 124,20 \mathrm{~mm}, \\
\text { diameter jarak bagi } \\
\left(\mathrm{d}_{1}\right) 120 \mathrm{~mm} \text { jumlah } \\
\text { gigi }\left(\mathrm{Z}_{2}\right)=60\end{array}$ & $\begin{array}{l}\text { Diameter kepala }\left(\mathrm{d}_{\mathrm{k} 1}\right) \\
124 \mathrm{~mm} \text {, diameter } \\
\text { jarak bagi }\left(\mathrm{d}_{1}\right) 120 \\
\text { mm jumlah gigi }\left(\mathrm{Z}_{2}\right) \\
60\end{array}$ & \multirow[b]{2}{*}{ Sesuai } \\
\hline & & $\begin{array}{l}\text { Roda gigi } \\
\text { yang } \\
\text { digerakkan }\end{array}$ & $\begin{array}{l}\text { Diameter kepala } \\
\left(\mathrm{d}_{\mathrm{k} 1}\right) 64 \mathrm{~mm} \text {, } \\
\text { diameter jarak bagi } \\
\left(\mathrm{d}_{1}\right) 60 \mathrm{~mm} \text { jumlah } \\
\text { gigi }\left(\mathrm{Z}_{2}\right)=30\end{array}$ & $\begin{array}{l}\text { Diameter kepala }\left(\mathrm{d}_{\mathrm{k} 1}\right) \\
64 \mathrm{~mm} \text {, diameter } \\
\text { jarak bagi }\left(\mathrm{d}_{1}\right) 60 \\
\mathrm{~mm} \text { jumlah gigi }\left(\mathrm{Z}_{2}\right) \\
30\end{array}$ & \\
\hline \multirow[t]{2}{*}{5} & \multirow[t]{2}{*}{ Poros } & $\begin{array}{l}\text { Poros } \\
\text { penggerak }\end{array}$ & Diameter $20 \mathrm{~mm}$ & Diameter $20 \mathrm{~mm}$ & \multirow{2}{*}{ Sesuai } \\
\hline & & $\begin{array}{l}\text { Poros yang } \\
\text { digerakkan }\end{array}$ & Diameter $20 \mathrm{~mm}$ & Diameter $20 \mathrm{~mm}$ & \\
\hline 6 & \multicolumn{2}{|l|}{ Bearing } & $\begin{array}{l}\text { Diameter dalam } 20 \\
\text { mm, tipe ball } \\
\text { bearing nomor } \\
\text { bantalan } 6004\end{array}$ & $\begin{array}{l}\text { Diameter dalam } 20 \\
\text { mm, tipe ball } \\
\text { bearing nomor } \\
\text { bantalan } 6004\end{array}$ & Sesuai \\
\hline \multirow[t]{2}{*}{7} & \multirow[t]{2}{*}{ Sabuk dan puli } & Sabuk & $\begin{array}{l}\text { Panjang keliling } \\
\text { sabuk } 889 \mathrm{~mm} \text {, } \\
\text { sabuk v tipe A } \\
\text { nomor } 35\end{array}$ & $\begin{array}{l}\text { Panjang keliling } \\
\text { sabuk } 889 \mathrm{~mm} \text {, } \\
\text { sabuk v tipe A nomor } \\
35\end{array}$ & Sesuai \\
\hline & & $\begin{array}{l}\text { Puli } \\
\text { penggerak }\end{array}$ & $\begin{array}{l}\text { Diameter } 127,00 \\
\mathrm{~mm}\end{array}$ & Diameter $127,00 \mathrm{~mm}$ & \\
\hline
\end{tabular}


Rancang Bangun Mekanisme Peningkat Putaran Bertenaga Sepeda Statis Dengan Keluaran 2700 Rpm Pada Sistem Alternator

\begin{tabular}{|c|c|c|c|c|c|}
\hline No. & \multicolumn{2}{|c|}{ Blok Rancangan } & Hasil & Indikator & Keterangan \\
\hline \multirow[t]{3}{*}{8} & \multirow[t]{3}{*}{$\begin{array}{l}\text { Penyangga roda } \\
\text { gigi, puli dan } \\
\text { alternator }\end{array}$} & $\begin{array}{l}\text { Penyangga } \\
\text { roda gigi } \\
\text { penggerak } \\
\text { dan knurling } \\
\text { wheels }\end{array}$ & $\begin{array}{l}\text { - } \text { Tegangan normal } \\
(\sigma) 0,0147 \mathrm{~N} / \mathrm{mm} \\
\text { - Tegangan yang } \\
\text { diijinkan }(\sigma) \\
42,875 \mathrm{~N} / \mathrm{mm} \\
-\quad \text { Tegangan } \\
\text { material S45C }(\sigma) \\
343 \mathrm{~N} / \mathrm{mm}\end{array}$ & $\begin{array}{l}\text { - Tegangan normal } \\
(\sigma) 0,0147 \mathrm{~N} / \mathrm{mm} \\
\text { - Tegangan yang } \\
\text { diijinkan }(\sigma) \\
42,875 \mathrm{~N} / \mathrm{mm} \\
\text { - Tegangan material } \\
\text { S45C }(\sigma) 343 \\
\mathrm{~N} / \mathrm{mm}\end{array}$ & Sesuai \\
\hline & & $\begin{array}{l}\text { Penyangga } \\
\text { roda gigi } \\
\text { yang } \\
\text { digerakkan } \\
\text { dan puli } \\
\text { penggerak }\end{array}$ & $\begin{array}{l}\text { - Tegangan normal } \\
(\sigma) 0,0143 \mathrm{~N} / \mathrm{mm} \\
\text { - } \text { Tegangan yang } \\
\text { diijinkan }(\sigma) \\
42,875 \mathrm{~N} / \mathrm{mm} \\
\text { - Tegangan } \\
\text { material S45C }(\sigma) \\
343 \mathrm{~N} / \mathrm{mm}\end{array}$ & $\begin{array}{l}\text { - Tegangan normal } \\
(\sigma) 0,0143 \mathrm{~N} / \mathrm{mm} \\
\text { - Tegangan yang } \\
\text { diijinkan }(\sigma) \\
42,875 \mathrm{~N} / \mathrm{mm} \\
\text { - Tegangan material } \\
\text { S45C }(\sigma) 343 \\
\mathrm{~N} / \mathrm{mm}\end{array}$ & Sesuai \\
\hline & & $\begin{array}{l}\text { Penyangga } \\
\text { alternator }\end{array}$ & $\begin{array}{l}\text { - } \text { Tegangan normal } \\
(\sigma) 0,0109 \mathrm{~N} / \mathrm{mm} \\
\text { - } \text { Tegangan yang } \\
\text { diijinkan }(\sigma) \\
42,875 \mathrm{~N} / \mathrm{mm} \\
\text { - Tegangan } \\
\text { material } \mathrm{S} 45 \mathrm{C}(\sigma) \\
343 \mathrm{~N} / \mathrm{mm}\end{array}$ & $\begin{array}{l}\text { - Tegangan normal } \\
(\sigma) 0,0109 \mathrm{~N} / \mathrm{mm} \\
\text { - Tegangan yang } \\
\text { diijinkan }(\sigma) \\
42,875 \mathrm{~N} / \mathrm{mm} \\
-\quad \text { Tegangan material } \\
\text { S45C }(\sigma) 343 \\
\mathrm{~N} / \mathrm{mm}\end{array}$ & Sesuai \\
\hline
\end{tabular}

\section{Uji Fungsi Rancangan}

Tabel 2. Uji fungsi rancangan

\begin{tabular}{|c|c|c|c|c|c|c|}
\hline No. & $\begin{array}{c}\text { Uji Fungsi } \\
\text { Rancangan }\end{array}$ & Referensi & Hasil & Indikator & $\begin{array}{c}\text { Tahap } \\
\text { Penerbangan }\end{array}$ & Keterangan \\
\hline 1 & \multirow{5}{*}{$\begin{array}{c}\text { Uji Putaran } \\
\text { mekanisme } \\
\text { peningkat } \\
\text { putaran } \\
\text { bertenaga } \\
\text { sepeda statis }\end{array}$} & \multirow{5}{*}{$\begin{array}{c}\text { Standard } \\
\text { Operating } \\
\text { Prosedure } \\
\text { Piper Archer } \\
\text { III PA-28-181 } \\
\text { (chapter } 2 \\
\text { Power } \\
\text { Setting) }\end{array}$} & $800 \mathrm{rpm}$ & $750 \mathrm{rpm}$ & Idle & Tercapai \\
\hline 2 & & & $1300 \mathrm{rpm}$ & $1000-1200 \mathrm{rpm}$ & Taxi & Tercapai \\
\hline 3 & & & $2200 \mathrm{rpm}$ & $2700 \mathrm{rpm}$ & Take off & Tidak tercapai \\
\hline 4 & & & $2200 \mathrm{rpm}$ & $2400 \mathrm{rpm}$ & Cruising & Tidak tercapai \\
\hline 5 & & & $1300 \mathrm{rpm}$ & $1000-1200 \mathrm{rpm}$ & landing & Tercapai \\
\hline
\end{tabular}

\section{Interpretasi Hasil Uji Rancangan}

Pengujian teoritis dilakukan dengan cara membandingkan hasil rancangan dengan kriteria rancangan. Kriteria tersebut didapat berdasarkan beberapa standar untuk merancang mekanisme peningkat putaran bertenaga sepeda statis untuk mencapai putaran maksimum $2700 \mathrm{rpm}$, dalam hal ini standar yang dijadikan acuan pada perancangan masih belum bisa terpenuhi sehingga alat yang dibuat belum tersertifikasi laik untuk digunakan di hangar 01 Teknik Pesawat Udara Sekolah Tinggi Penerbangan Indonesia. Dari tabel (3) dan (4). Berdasarkan hasil pengujian yang sudah dilakukan pada rancangan tersebut secara umum dapat 
bekerja sesuai desain perancangan namun belum dapat mencapai putaran maksimum yang diinginkan karena tenaga otot kaki manusia mengayuh sepeda terbatas

\section{Kesimpulan dan saran \\ Kesimpulan}

Dari tahapan perancangan dapat disimpulkan sebagai berikut :

1. Dalam memilih dudukan sepeda jenis friction bicycle trainer dapat disimpulkan bahwa dudukan sepeda mampu menahan beban sepeda $15 \mathrm{~kg}$, mampu menahan beban pengayuh 70 $\mathrm{kg}$ dan sesuai untuk ukuran roda sepeda 26" dengan rear wheel axle $7 "$ ".

2. Dalam merancang adjustment penghubung antara dudukan sepeda dan penyangga roda gigi dapat disimpulkan bahwa panjang batang berulir yang digunakan $400 \mathrm{~mm}$, ulir kasar metris M16 dengan diameter luar $16 \mathrm{~mm}$, diameter dalam 13,835 $\mathrm{mm}$.

3. Dalam menentukan knurling wheel jenis diamond pattern knurling dapat disimpulkan bahwa diameter yang digunakan $60 \mathrm{~mm}$ dengan permukaan diamond pattern knurling.

4. Dalam merancang roda gigi penggerak (gigi lurus) dan roda gigi yang digerakkan (gigi lurus) dapat disimpulkan bahwa roda gigi penggerak yang digunakan memiliki diameter kepala $124 \mathrm{~mm}$, diameter jarak bagi $120 \mathrm{~mm}$, jumlah gigi 60 dan roda gigi yang digerakkan dengan diameter kepala $64 \mathrm{~mm}$, diameter jarak bagi $60 \mathrm{~mm}$, jumlah gigi 30 .

5. Dalam merancang poros (roda gigi, puli dan knurling wheel) dapat disimpulkan bahwa diameter poros yang digunakan $20 \mathrm{~mm}$ dengan ukuran pasak $7 \times 7$.

6. Dalam memilih bearing dapat disimpulkan bahwa tipe bearing yang digunakan adalah ball bearing dengan nomor bantalan 6004 diameter dalam $20 \mathrm{~mm}$ dan diameter luar $42 \mathrm{~mm}$.

7. Dalam memilih sabuk dan puli dapat disimpulkan bahwa sabuk yang digunakan adalah sabuk $\mathrm{v}$ tipe $\mathrm{A}$ nomor 35 dengan panjang keliling sabuk $889 \mathrm{~mm}$ dan diameter puli 127 $\mathrm{mm}$.

8. Dalam merancang penyangga (roda gigi, puli dan alternator) dapat disimpulkan bahwa penyangga (roda gigi penggerak dan knurling wheel) memiliki tegangan normal $\sigma 0,0147$ $\mathrm{N} / \mathrm{mm}^{2}$, penyangga (roda gigi yang digerakkan dan puli penggerak) memiliki tegangan normal $\sigma 0,0143$ $\mathrm{N} / \mathrm{mm}^{2}$ dan penyangga alternator memiliki tegangan normal $\sigma 0,0109$ $\mathrm{N} / \mathrm{mm}^{2}$ serta masing-masing penyangga menggunakan material S45C dengan tegangan ijin material $42,875 \mathrm{~N} / \mathrm{mm}^{2}$ dan tegangan material $343 \mathrm{~N} / \mathrm{mm}^{2}$.

\section{Saran}

Adapun saran yang diberikan oleh penulis sebagai berikut :

1. Dalam menentukan knurling wheel jenis diamond pattern knurling disarankan melapisi permukaan knurling wheel dengan bahan yang sesuai dengan bahan ban sepeda agar ban sepeda tidak terkikis atau mengganti knurling wheel dengan sprocket dan rantai yang terhubung dengan sprocket sepeda agar tidak 
Rancang Bangun Mekanisme Peningkat Putaran Bertenaga Sepeda Statis Dengan Keluaran 2700 Rpm Pada Sistem Alternator

langsung bergesekan dengan permukaan ban sepeda sehingga permukaan ban sepeda tidak terkikis.

2. Dalam merancang roda gigi penggerak (gigi lurus) dan roda gigi yang digerakkan (gigi lurus) disarankan memilih jenis roda gigi dengan getaran yang minimum dan tidak berisik saat mengalami putaran yang tinggi.

3. Dalam memilih sabuk dan puli disarankan memilih jenis sabuk yang tidak mudah aus karena gesekan akibat putaran yang tinggi dan memilih diameter puli penggerak dengan ukuran yang lebih besar agar nilai rpm yang diinginkan dapat tercapai.

4. Dalam proses memutar knurling wheel disarankan mengatur adjustment penghubung antara bicycle trainer dan penyangga roda gigi agar permukaan ban sepeda dan permukaan knurling wheel bersentuhan sepenuhnya untuk meminimalisir pengikisan permukaan ban sepeda dan atur tekanan ban yang diperlukan agar tenaga torsi mengayuh sepeda saat memutar knurling wheel tidak terlalu berat.

\section{DAFTAR PUSTAKA}

Amanto, H., \& Daryanto. (1999). Ilmu Bahan. Jakarta: PT Bumi Aksara.

\section{Aviation Maintenance Technician} Handbook Airframe, Volume 1. (2012). Federal Aviation Administration.

Irawan, A. P. (2016). Perancangan Sistem Transmisi Roda Gigi. Yogyakarta: PT Kanisius.

Khurmi, R.S., Gupta, J.K. (2005). A Text Book of Machine Design. New
Delhi: Eurasia Publishing House Ltd.

Lycoming. (2005). Operator's Manual Lycoming O-360, HO-360, IO360, AIO-360, HIO-360 \& TIO360 Series ( $8^{\text {th }}$ edition).

Mocanu, S., Ungureanu, A., \& Varbanescu, R. (2015). Bike Powered Electricity Generator. Asia Fasific Journal of Multidicinary Research, Vol. 3.

Mott, R. L. (2004). Machine Element in Mechanical Design (fourth). Upper Saddle River, New Jersey Colombus, Uhio: Pearson.

Nurdjito, \& Arifin, A. (2015). Handout Pemesinan Bubut. Yogyakarta.

Sularso, \& Suga, K. (2004). Dasar Perencanaan Dan Pemilihan Elemen Mesin. Jakarta: Pradnya Paramita.

Young, H. D., \& Freedman, R. A. (2002). Fisika Universitas Edisi Kesepuluh Jilid 1. Jakarta: Erlangga. 